\title{
Exposure, infection, systemic cytokine levels and antibody responses in young children concurrently exposed to schistosomiasis and malaria
}

\author{
NATSUKO IMAI ${ }^{1}$, NADINE RUJENI ${ }^{1}$, NORMAN NAUSCH ${ }^{1}$, CLAIRE D. BOURKE $^{1}$, \\ LAURA J. APPLEBY ${ }^{1}$, GRAEME COWAN ${ }^{1}$, REGGIS GWISAI ${ }^{4}$, NICHOLAS MIDZI ${ }^{2}$, \\ DAVID CAVANAGH ${ }^{1}$, TAKAFIRA MDULUZA ${ }^{3}$, DAVID TAYLOR ${ }^{1 \dagger}$ and \\ FRANCISCA MUTAPI ${ }^{1} *$ \\ ${ }^{1}$ Institute of Immunology and Infection Research, School of Biological Sciences, ${ }^{1 \dagger}$ Centre for Infectious Diseases, \\ University of Edinburgh, Ashworth Laboratories, King's Buildings, West Mains Rd, Edinburgh, EH9 3FT \\ ${ }^{2}$ National Institute of Health Research, Box CY 570, Causeway, Harare, Zimbabwe \\ ${ }^{3}$ Department of Biochemistry, University of Zimbabwe, P.O. Box 167, Mount Pleasant, Harare, Zimbabwe \\ ${ }^{4}$ Murewa District Hospital, Murewa, Zimbabwe.
}

(Received 29 October 2010; revised 24 February and 25 March 2011; accepted 25 June 2011; first published online 4 August 2011)

\section{SUMMARY}

Despite the overlapping distribution of Schistosoma haematobium and Plasmodium falciparum infections, few studies have investigated early immune responses to both parasites in young children resident in areas co-endemic for the parasites. This study measures infection levels of both parasites and relates them to exposure and immune responses in young children. Levels of IgM, IgE, IgG4 directed against schistosome cercariae, egg and adult worm and IgM, IgG directed against P. falciparum schizonts and the merozoite surface proteins 1 and 2 together with the cytokines IFN- $\gamma$, IL-4, IL-5, IL-10 and $\mathrm{TNF}-\alpha$ were measured by ELISA in $95 \mathrm{Zimbabwean}$ children aged $1-5$ years. Schistosome infection prevalence was $14 \cdot 7 \%$ and that of Plasmodium infection was $0 \%$ in the children. $43.4 \%$ of the children showed immunological evidence of exposure to schistosome parasites and 13\% showed immunological evidence of exposure to Plasmodium parasites. Schistosomespecific responses, indicative of exposure to parasite antigens, were positively associated with cercariae-specific IgE responses, while Plasmodium-specific responses, indicative of exposure to parasite antigens, were negatively associated with responses associated with protective immunity against Plasmodium. There was no significant association between schistosome-specific and Plasmodium-specific responses. Systemic cytokine levels rose with age as well as with schistosome infection and exposure. Overall the results show that (1) significantly more children are exposed to schistosome and Plasmodium infection than those currently infected and; (2) the development of protective acquired immunity commences in early childhood, although its effects on infection levels and pathology may take many years to become apparent.

Key words: Young children, schistosome, Plasmodium, co-infection, immunity, antibody, cytokine, human.

\section{INTRODUCTION}

There is considerable overlap in the geographical distribution of the two human parasites, Schistosoma haematobium and Plasmodium falciparum, and the prevalences of both parasites in exposed individuals rise with age, peaking in childhood. Schistosome infection in children below 5 years of age had, until recently, largely been ignored as a result of two previous misconceptions; (1) that such young children are not sufficiently exposed to water containing viable schistosome cercariae to acquire significant levels of

* Corresponding Author: Dr Francisca Mutapi, Institute of Immunology and Infection Research, School of Biological Sciences, University of Edinburgh, Ashworth Laboratories, King's Buildings, West Mains Rd, Edinburgh, EH9 3JT. Email: f.mutapi@ed.ac.uk. Tel: + 44131650 8662. Fax: + 441316505450 .

\$ Currently: Botswana Harvard Aids Institute, P. Bag BO 320, Gaborone, Botswana. infection, and (2) that low levels of infection carried by pre-school children did not translate into severe morbidity (Stothard and Gabrielli, 2007). With the growing evidence that children aged 5 years and below do carry significant levels of schistosome infection (Mafiana et al. 2003; Sousa-Figueiredo et al. 2008; Uneke and Egede, 2009; Garba et al.2010), and morbidity (Garba et al. 2010) and the indication that this same age group can suffer from severe malaria (Oduro et al. 2007), there is a need to understand the interaction between the two parasites in these young children in terms of disease aetiology and impact on child health and development. The pathophysiology of both parasitic infections is immune-mediated, such as cerebral malaria or schistosome granuloma and fibrosis (Mott and Chen, 1989; Maitland and Marsh, 2004). However co-infection is known to modulate immune responses, potentially altering the pathophysiological and immunological profiles of disease (Booth et al. 2004b,c). To date there is a

Parasitology (2011), 138, 1519-1533. (C) Cambridge University Press 2011. The online version of this article is published within an Open Access environment subject to the conditions of the Creative Commons Attribution-NonCommercial-ShareAlike licence < http:// creativecommons.org/licenses/by-nc-sa/2.5/>. The written permission of Cambridge University Press must be obtained for commercial re-use. 
paucity of studies describing the burden of Schistosoma haematobium infection in children aged 5 years and below and even fewer studies characterizing the early schistosome specific immune responses in these children. There are relatively more studies of Plasmodium-specific immune responses in young children but fewer studies characterizing schistosome and Plasmodium-specific responses in children concurrently exposed to both parasites.

Investigating the earliest immune responses resulting from exposure to schistosome and Plasmodium antigens in childhood not only informs on the nature and development of pathological/protective responses, but also on the phenotype of systemic immune responses at this young age. Therefore we have investigated the relationship between exposure to both parasites and the development of parasitespecific antibody responses. The study focused on immune responses indicative of recent exposure to infection as well as immune responses associated with resistance to infection/re-infection. Parasite-specific $\mathrm{IgM}$ responses are associated with recent exposure to parasites and several studies have shown this to be true for both Plasmodium and schistosome parasites (Mutapi et al. 1997; Ndhlovu and Woolhouse, 1996; Naus et al. 2003a). In Plasmodium infections, IgG1 and IgG3 antibody sub-classes are associated with protection against the merozoite surface proteins (MSP) antigens (Bouharoun-Tayoun and Druihle, 1992; Cavanagh et al. 2004). Studies on S. haematobium indicate that the balance between adult schistosome-specific $\mathrm{IgE}$ and $\mathrm{IgG} 4$ is one of the key indicators of the development of protective immunity to infection (Hagan et al. 1991) while anti-cercariae $\mathrm{IgE}$ and $\mathrm{IgG} 4$ responses are associated with the hypersensitivity reaction causing cercarial dermatitis (Kourilova et al. 2004; Lichtenbergova et al. 2008). Anti-egg IgG4 responses have been associated with pathology in S. mansoni infected Brazilians (Silveira et al. 2002) and anti-egg $\operatorname{IgE}$ has been associated with immunity to re-infection with $S$. japonicum (Zhang et al. 1997). Therefore, this study focused on total IgM IgG responses against crude Plasmodium schizont antigen (to determine exposure to P. falciparum parasites), IgM against schistosome antigens (to determine exposure to $S$. haematobium infections), $\mathrm{IgG}$ responses against two P. falciparum vaccine candidates, merozoite surface protein (MSP)1 and MSP-2 we have previously reported on from Zimbabwean populations (Reilly et al. 2008) and anti-schistosome $\mathrm{IgE}$ and $\mathrm{IgG} 4$ as indicators of the development of putatively protective acquired immunity and as risk factors for immunopathology.

Cytokines contribute both to infection-related pathological processes and the development of protective immunity to these parasites (Booth et al. 2004a; Hunt and Grau, 2003). Interleukin (IL)-10 and interferon-gamma (IFN- $\gamma)$ are involved in isotype switching to protective $\mathrm{IgG}$ sub-classes in
Plasmodium infections (Garraud et al. 2003), while IL-4, IL-5 and IL-10 appear to be important for the development of resistance to schistosome infection (Pearce and MacDonald, 2002). There is a growing body of evidence suggesting that there is a significant interaction in the development of protective immunity and pathology in individuals co-infected with these parasites (Arinola, 2005; Diallo et al. 2010; Remoue et al. 2003; Wilson et al. 2008), but there are few studies in young children. A study in Senegal compared systemic cytokine levels in children aged $7-15$ years to those in adults aged over 30 years and showed that children co-infected by $S$. haematobium had higher levels of IFN- $\gamma$ and sTNF-RII compared to children infected only by $P$. falciparum. In contrast, co-infected adults showed a significant increase in IFN- $\gamma$, IL-10, TGF- $\beta$, s'TNF-RI and sTNF-RII, RANTES and the IL-10/TNF- $\alpha$ ratio (Diallo et al. 2004). The role of childhood infections in determining future responses mounted to self and non-self antigens is an area of active interest (van den Biggelaar and Holt, 2010).

For this study, systemic cytokines indicative of CD4 + T cell-mediated T helper (Th)1 and Th2-type responses were selected for investigation, as these are amongst the main immunological correlates of pathology and protective immunity to Plasmodium and schistosome infections (Pearce and MacDonald, 2002; Maizels and Yazdanbakhsh, 2003; Hunt and Grau, 2003; Booth et al. 2004a; Lyke et al. 2004; Awandare et al. 2006). IFN- $\gamma$, and TNF- $\alpha$ are markers of 'Th1 responses, IL-4 and IL-5 are markers for Th2 responses, and IL-10, originally classified as both a Th1 and Th2 cytokine in humans (Del Prete et al. 1993), is now also seen as a marker for immunomodulation and regulatory responses (van den Biggelaar et al. 2000; Hesse et al. 2004; McKee and Pearce, 2004). Regulatory responses appear to play an important role in limiting immunopathology in single-species infections (Malaquias et al. 1997; Hunt and Grau, 2003; Booth et al. 2004a) and may also be important in malaria-schistosome coinfection.

The aim of this study was to determine the level of infection with, and exposure to $S$. haematobium and $P$. falciparum in children aged $1-5$ years resident in villages endemic for both parasites and relate this to the development of parasite-specific immune responses and levels of systemic cytokines.

\section{MATERIALS AND METHODS}

\section{Study area}

The study was conducted in two villages, Magaya and Chitate, in the Mashonaland East Province of Zimbabwe $\left(31^{\circ} 90^{\prime} \mathrm{E} ; 17^{\circ} 63^{\prime} \mathrm{S}\right)$ where S. haematobium is endemic. The participants are involved in ongoing studies on the control and immuno-epidemiology of 
human schistosomiasis. The main activity in these villages is subsistence farming and human water contact is frequent with at least 4 contacts/person/ week (assessed by questionnaire) due to insufficient safe water and sanitation facilities. The rivers in the two villages differ in their temporal patterns; those in Magaya are mostly perennial while those in Chitate are seasonal, leading to different schistosome transmission dynamics. Older children are exposed to infective water actively while younger children are also exposed passively (e.g. sitting in a container with infective water) (Stothard and Gabrielli, 2007) as indicted by questionnaire responses of their parents/ guardians. Plasmodium falciparum is the predominant species of malaria in Zimbabwe (Taylor and Mutambu, 1986) where malaria transmission is largely unstable in nature. Approximately $5 \cdot 5$ million people out of a total population of 12.7 million live in malarious areas (Stanley Midzi et al. 2004). Out of the 56 districts in Zimbabwe, malaria transmission occurs in 42. In 2002, a revised stratification based on a national parasite prevalence survey, Health Management Information Systems (HMIS) data, entomological data and expert opinion classified our study area under the sporadic transmission regions with low transmission (Mabaso et al. 2005, 2006) meaning that this is a mesoendemic area for Plasmodium transmission and malaria (Mharakurwa et al. 2004). The peak $P$. falciparum transmission occurs from February to May (Mharakurwa et al. 2004) and the annual incidence of malaria in the area is 1-10 cases/1000 people (Mabaso et al. 2006; Hay et al. 2009). The study was conducted in February.

\section{Ethical statement}

Permission to conduct the study in the region was obtained from the Provincial Medical Director. Institutional and ethical approval was received from the University of Zimbabwe and the Medical Research Council of Zimbabwe respectively. At the beginning of the study, parents and guardians of participating children had the aims and procedures of the project explained fully in the local language, Shona, and written consent was obtained from participants' parents/guardian before enrolment into the study. After collection of all samples, all participants and their parents/guardians were offered anthelmintic treatment with the recommended dose of praziquantel (40 $\mathrm{mg} / \mathrm{kg}$ of body weight).

\section{Sample collection and inclusion criteria}

Stool and urine specimens were collected from each participant on 3 consecutive days and examined microscopically for S. haematobium, S. mansoni and geo-helminths following standard procedures (Katz et al. 1972; Mott, 1983). The formol-ether concentration method was performed as previously described (Cheesbrough, 1998; Midzi et al. 2008) on a random sample of the stool samples to confirm results obtained by the Kato-Katz technique. For infants, samples were collected overnight if it was not possible to collect a sample on the spot. A maximum of $5 \mathrm{ml}$ of venous blood was collected and processed as previously described (Mutapi et al. 2008) for Plasmodium detection cytokine and antibody assays. Thick and thin smear slides were prepared per participant upon blood collection for the microscopic detection of Plasmodium parasites. Results from these examinations were confirmed using the rapid Paracheck dipstick (Orchid Biomedical Systems). Plasma samples were stored at $-20{ }^{\circ} \mathrm{C}$ and freighted frozen to Edinburgh where they were thawed for the assays described below.

In order to be included in the study, participants had to meet all the following criteria: (1) have been resident in the study area since birth; (2) provided at least two urine and two stool samples on consecutive days; (3) be negative for intestinal helminths including $S$. mansoni (no-one was excluded on this criteria as everyone was negative for these infections as is reported in other parts of Zimbabwe (Midzi et al. 2010) and (4) have given a blood sample for the collection of sera. A total of 95 (54 from Magaya and 41 from Chitate) participants aged 1-5 years met these criteria and formed our study population.

\section{Parasite antigens}

Lyophilized soluble S. haematobium adult worm antigen (WWH), cercariae antigen (CAP) and soluble egg antigen (SEA) were obtained from the Theodor Bilharz Institute (Egypt) and reconstituted as described elsewhere (Mutapi et al. 2005). The parasite strain is one used for our previous immunoepidemiology studies (Milner et al. 2010; Mutapi et al. 2008; Reilly et al. 2008). The P. falciparum antigens were those previously used in a study in Zimbabwe (Reilly et al. 2008) and included crude schizont antigen and the recombinant merozoite surface protein (MSP) antigens prepared in Escherichia coli, MSP-1 19 antigen also known as p190, gp195, (Burghaus and Holder, 1994; Holder et al. 1994) and two full-length recombinant MSP-2 antigens, namely CH150/9 (5/6) and Dd2 (13/14) (Metzger et al. 2003). MSP-2 has 2 serotypes: CH150/9 5/6 is taken from serotype A (3D7-like), and Dd2 belongs to serotype $\mathrm{B}$ (FC27-like).

\section{Antibody assays}

IgM, IgE and IgG4 specific for schistosome antigens from the three life stages (cercariae, egg and adult) were measured by indirect enzyme linked immunosorbent assays (ELISA) as previously described 
(Mutapi et al. 1997). P. falciparum-specific responses ( $\mathrm{IgM}$ and $\mathrm{IgG}$ ) were also measured by ELISA as previously described (Aribot et al. 1996; Oeuvray et al. 1994; Theisen et al. 1998). Briefly, ELISAs were conducted in duplicate for each sample using ELISA plates (Nunc-Immulon, Denmark) that were coated with $50 \mu \mathrm{l} /$ well of $50 \mathrm{ng} / \mathrm{ml}$ antigen for recombinant antigens and $1 \mu \mathrm{g} / \mathrm{ml}$ for both crude antigens in $60 \mathrm{~mm}$ carbonate-bicarbonate buffer ( $\mathrm{pH} 9 \cdot 6)$ and incubated overnight at $4{ }^{\circ} \mathrm{C}$. Plates were blocked with $200 \mu \mathrm{l} /$ well of skimmed milk (5\% milk in phosphate buffered saline (PBS)/0.03\% Tween 20) for $1 \mathrm{hr}$ and washed three times in PBS/Tween 20, which was used for all washes. $100 \mu \mathrm{l}$ of serum was added to each well at 1:100 dilution for all assays; plates were incubated at $37^{\circ} \mathrm{C}$ for 2 hours and then washed three times. $100 \mu \mathrm{l}$ of subclass-specific monoclonal antibody (IgM for crude antigens and IgG for both crude and recombinant antigens, both from Dako UK) were added at 1:1000 dilution for crude antigens and 1:2000 dilution for recombinant antigens. Plates were incubated overnight at $4{ }^{\circ} \mathrm{C}$, washed six times and $50 \mu 1$ of ABTS substrate solution (KPL, Canada) was added, before the absorbance was read at $405 \mathrm{~nm}$. Negative controls from 5 age-matched schistosome and Plasmodium naïve European donors (aged 1-5 years old) were included in duplicate on each of the IgM plates to indicate cut-off points for reactivity, while 2 negative controls were included on the rest of the plates.

The anti-schistosome egg IgM antibodies were also used diagnostically based on exposure to egg antigens as recently reported in a study in preschool children exposed to $S$. mansoni infection in Uganda (Stothard et al. 2011). Anti-cercariae IgM and antischizont IgM were used to indicate recent exposure to schistosome cercariae and Plasmodium schizonts as previously described for schistosomiasis (Woolhouse et al. 2000) and Plasmodium respectively (Naus et al. $2003 b$ ). To determine if children showed recent exposure to parasites (schistosome cercariae, worm or egg, or Plasmodium schizonts), levels of the parasitespecific antibodies (optical densities) had to be greater than the mean +2 standard deviations of the negative controls.

\section{Cytokine assays}

Circulating levels of IFN- $\gamma$, IL-4, IL-5, IL-10 and TNF- $\alpha$ in plasma samples were conducted using capture ELISA with antibody capture/detection pairs and standards from BD Biosciences following previously published protocols (Joseph et al. 2004; Milner et al. 2010) and manufacturer's guidelines. All assays were conducted in duplicate. People with cytokine levels above zero $\mathrm{ng} / \mathrm{ml}$ (after the subtraction of the blank control) were denoted positive for the cytokine while those with concentrations of zero $\mathrm{ng} / \mathrm{ml}$ or below were designated as having no detectable levels of the cytokine.

\section{Statistical analyses}

Infection prevalence was compared between villages by Chi-squared test. For analyses on antibody levels the continuous optical density data were used to ensure that the early dynamics of the parasite-specific immune responses could be captured even in children producing low levels of the antibodies. Thus levels of antibodies directed against the different schistosome crude antigens were compared using the non parametric Kruskal Wallis test (data did not satisfy the assumptions of parametric tests) while antibody responses against $P$. falciparum crude antigens were compared using the Mann-Whitney Test. The effects of host sex (categorical, male and female), age ( 3 categories, 1-3 years, 3.1 yrs -4 years and $4.1-5$ years to give sufficiently large sample sizes for statistical analyses), village (categorical, Magaya and Chitate) and schistosome infection level either as a categorical variable (egg positive or egg negative) or continuous variable $(\log (x+1)$ transformed) on antibody level (square root transformed) were tested using an analysis of variance. Sequential sums of squares were used to account for variation due to all other factors before testing for the effects of schistosome infection level and the interaction between village and age group (to determine the presence of a peak shift) (Mutapi et al. 1997).

Given that the study measured several immune variables, i.e. 9 schistosome-specific responses, 5 Plasmodium-specific responses and 5 cytokines, reducing the number of variables was used as a means of identifying dynamics of exposure and the development of parasite-specific acquired immunity. Thus all the parasite-specific antibody variables and cytokine variables were reduced into uncorrelated variables by factor analysis, a standard technique for reducing multivariate data to its main independent features, by transforming several correlated variables into fewer uncorrelated variables called principal components (Sokal and Rohlf, 1995). The components are extracted according to the amount of variation in the data they explain, so the first component explains the most variation and each subsequent component is included if it explains a significant amount of the remaining variation within the data (Sokal and Rohlf, 1995). Principal components with eigenvalues greater than one were extracted by regression analysis and an extracted component was considered reliable if it had one or more of the original variables with factor loadings $\geqslant 6$ or $\leqslant-6$ and below. Principal component regression factor scores for each participant were used in analyses of variance to determine their relationship with host factors (sex, age group, village, schistosome infection intensity and the 
Table 1. Schistosome infection level in the study population

\begin{tabular}{|c|c|c|c|c|c|c|}
\hline & \multicolumn{3}{|c|}{ Magaya (High infection area) } & \multicolumn{3}{|c|}{ Chitate (low infection area) } \\
\hline & $\begin{array}{l}\text { Infection } \\
\text { intensity } \\
\text { range } \\
\text { (sample size) }\end{array}$ & $\begin{array}{l}\text { Infection } \\
\text { intensity } \\
\text { mean* } \\
(\mathrm{SEM})^{* *}\end{array}$ & $\begin{array}{l}\text { Infection } \\
\text { prevalence }\end{array}$ & $\begin{array}{l}\text { Infection } \\
\text { intensity } \\
\text { range } \\
\text { (sample size) }\end{array}$ & $\begin{array}{l}\text { Infection } \\
\text { intensity } \\
\text { mean } \\
(\mathrm{SEM})\end{array}$ & $\begin{array}{l}\text { Infection } \\
\text { prevalence }\end{array}$ \\
\hline $1-3$ years old & $0-22(7)$ & $3 \cdot 14(3 \cdot 14)$ & $14 \cdot 3 \%$ & $0(11)$ & 0 & 0 \\
\hline $3.1-4$ years old & $0-458(18)$ & $25 \cdot 44(25 \cdot 44)$ & $6 \cdot 6 \%$ & $0(19)$ & 0 & 0 \\
\hline $4.1-5$ years old & $0-268(31)$ & $16 \cdot 26(9 \cdot 09)$ & $35 \cdot 5 \%$ & $0-1(9)$ & $0 \cdot 04(0 \cdot 04)$ & $11 \cdot 1$ \\
\hline Total & $0-458(56)$ & $17 \cdot 57(9 \cdot 50)$ & $23 \cdot 2 \%$ & $0-1(39)$ & $0 \cdot 01(0 \cdot 01)$ & $2 \cdot 6$ \\
\hline
\end{tabular}

* = arithmetic mean.

** $\mathrm{SEM}=$ Standard error of the mean

village $\times$ age group interaction). After exploratory plots, one tailed Pearson correction analyses was conducted to determine the relationship between PCs while controlling for host sex, age group, village, and schistosome infection intensity.

RESULTS

\section{Parasite infection levels}

The children came from 2 villages endemic for $S$. haematobium infection; an initial survey of 1980 permanent residents of the study villages aged 1-80 years showed that schistosome infection prevalence was significantly higher in Magaya (prevalence $=69 \%, 95 \%$ CI: $63 \%$ to $75 \%$ ) than in Chitate (prevalence $=14 \%, 95 \%$ CI: $11 \%$ to $18 \%$ ) $\left(\chi^{2}=187, \mathrm{df}=1, P<0 \cdot 001\right)$, as was infection intensity $58 \mathrm{eggs} / 10 \mathrm{ml}$ urine (Standard error of the mean $(\mathrm{SEM})=8 \cdot 02)$ and $15 \mathrm{eggs} / 10 \mathrm{ml}$ urine $(\mathrm{SEM}=4 \cdot 17)$ respectively $\left(\mathrm{F}_{1,612}=201, P<0 \cdot 001\right)$. The World Health Organisation's classification guidelines classify Magaya as a high infection area (i.e. more than 50\% of the population infected) and Chitate as a low infection area (i.e. less than $10 \%$ of the population infected) (WHO, 2002). Amongst the 1-5 year olds participating in this study, the overall prevalence of S. haematobium infection was $14 \cdot 7 \%,(95 \% \mathrm{CI}=13-$ $36 \cdot 4 \%$ ) with 13 out of 54 children in Magaya being infected and only 1 child from Chitate being infected (prevalence $=2 \cdot 6 \%, 95 \% \mathrm{CI}=0.06 \%-13.5 \%$ ). Infection prevalence was significantly different in the two villages $\left(\mathrm{X}^{2}=7 \cdot 8, P<0 \cdot 001\right)$. Similarly infection intensity was significantly different in the two villages $\left(\mathrm{F}_{1,94}=5 \cdot 88, P=0 \cdot 020\right)$ with mean infection intensity in Magaya being 17.5 eggs per $10 \mathrm{ml}$ urine $(\mathrm{SEM}=9 \cdot 5)$ and infection rage $0-458 \mathrm{eggs} / 10 \mathrm{ml}$ urine and the only infected child in Chitate excreting $1 \mathrm{egg} / 10 \mathrm{ml}$ urine. While the presence of schistosome infection was apparent from the youngest age group in Magaya, the high infection area (age of youngest egg positive child: 3 years 0 months), the only child excreting schistosome eggs in Chitate, the low infection area, was aged 4 years and 6 months. Schistosome infection levels in Magaya and Chitate partitioned by age are shown in Table 1 . These infection patterns were consistent when anti-egg IgM responses were used for diagnosing schistosome infection, which gave a prevalence of $24.4 \%$ in Magaya $(95 \% \mathrm{CI}=12 \cdot 9-39 \cdot 5 \%)$ (the youngest infected person here was 3 years of age) and $7 \cdot 7 \%$ in Chitate $(95 \% \mathrm{CI}=1 \cdot 6-20 \cdot 9 \%)$ (the youngest infected person here was 4 years of age). The age profiles of schistosome infection measured by egg counts was comparable to that measured by the presence of eggspecific immune responses in both villages as shown in Fig. 1. There were no P. falciparum parasites detected in the blood of any of the children by thick or thin smears and these results were confirmed by the rapid Paracheck serological test.

\section{Parasite-specific antibody responses}

Schistosome-specific responses directed against cercariae and eggs were significantly higher than those directed against adult worms (Table 2). When compared to Zimbabweans, schistosome- and Plasmodium-naïve European controls had lower means and ranges of schistosome-specific antibodies as shown in Fig. 1A. When using these controls as cut-offs (i.e. mean \pm 2 standard deviations), $43 \cdot 4 \%$ of the children had levels of anti-cercariae IgM above those of European donors, indicating that these children had been exposed to cercariae antigens. $27.4 \%$ of the children (all of whom had anti-cercariae IgM levels above those of the controls) had anti-adult worm responses, above those of the controls. Thus significantly more children had been exposed to schistosome antigens than the proportion who were excreting schistosome eggs $\left(\mathrm{X}^{2}=9 \cdot 07, P=0 \cdot 005\right)$. Furthermore, the proportion of children with antischistosome IgM levels (against all life stages) above that of the controls was significantly higher in Magaya $(60 \%)$ compared to Chitate $(23 \cdot 7 \%$, $\left.\mathrm{X}^{2}=10 \cdot 7, P=0 \cdot 001\right)$. In both villages, the proportion 

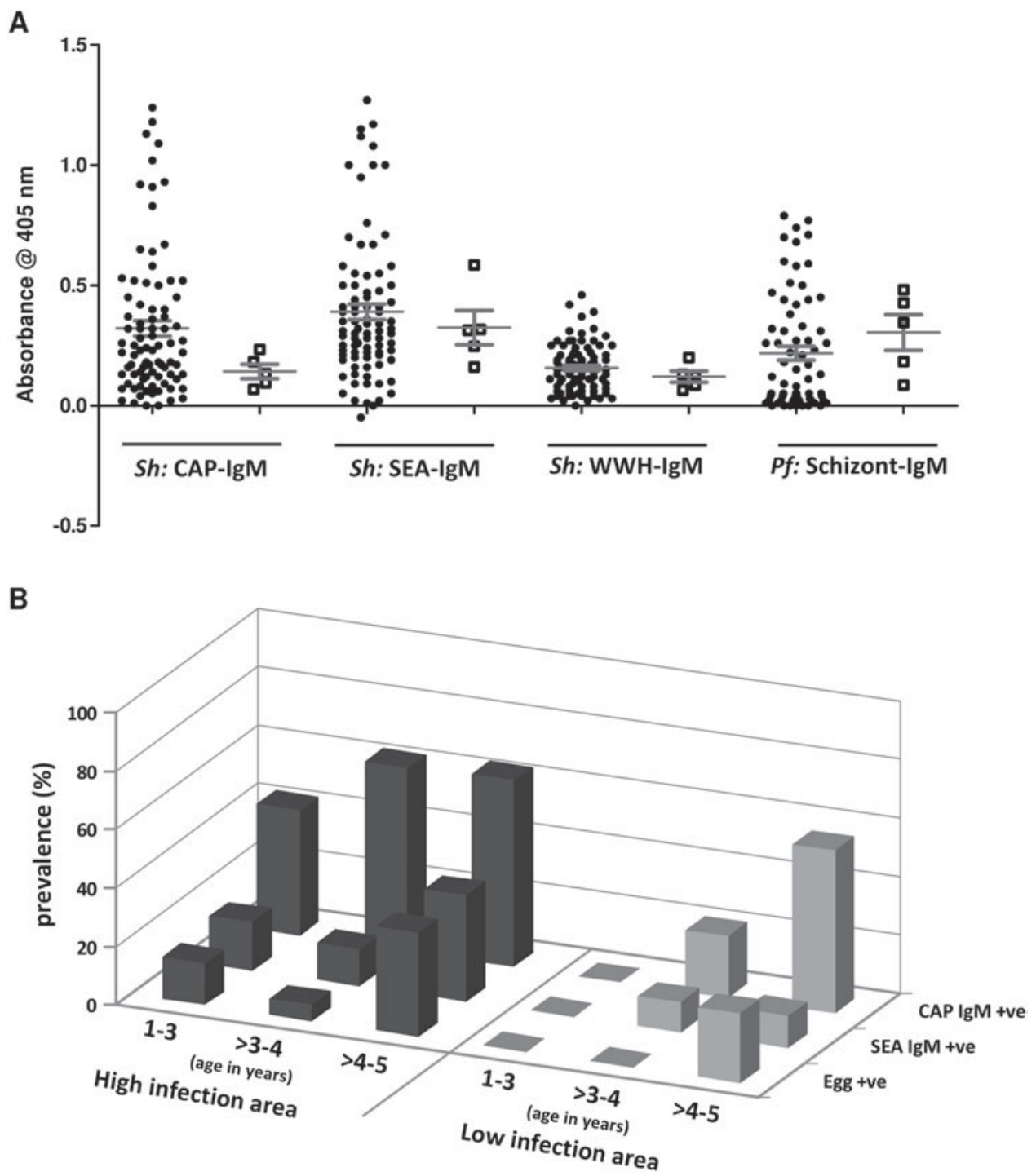

Fig. 1. Parasite-specific IgM responses. (A) Comparison of individuals' parasite-specific IgM antibody levels in the Zimbabwean study group (closed circles) compared to European donors (open squares) for each parasite antigen for Schistosoma haematobium $(\mathrm{Sh})(\mathrm{CAP}=$ cercariae antigen preparation, $\mathrm{SEA}=$ soluble egg antigen, $\mathrm{WWH}=$ soluble adult worm antigen) and Plasmodium falciparum (Pf) $(\mathrm{Scz}=$ schizont). Mean and standard error of the mean is shown for each population. (B) Comparison of schistosome infection prevalence determined by egg count and by egg-specific antibodies vs. presence and exposure to parasite antigens. The figure shows the percentage of people with at least 1 egg in $10 \mathrm{ml}$ urine (Egg + ve), the percentage of people with anti-egg IgM levels (SEA IgM + ve) above the control cut-off and, the percentage of people with anti-cercariae (CAP IgM + ve) above the control cut-off taken to indicate exposure to cercariae.

of children showing evidence of exposure to schistosomes rose with age although this was not statistically significant (Fig. 1B). Titres of Plasmodium crude schizont-specific IgM were significantly higher than those for $\operatorname{IgG}(Z=-5,53, P<0 \cdot 001)$, whilst among the recombinant antigens; titres were highest against MSP-2(Dd2) antigen. 13\% of the children had antischizont IgM levels above those of the negative controls whose raw data (antibody titres) are shown in Fig. 1A.

Further analyses to determine the factors associated with antibody levels showed that there were no significant differences in antibody levels in male compared to female children. Levels of IgM directed against all schistosome parasite stages rose with host age (Fig. 2A) regardless of their village of residence; however this relationship was significant only for anti-worm IgM (Table 2). Age also had a significant effect on anti-cercariae IgG4. Anti-MSP-2(Dd2) rose with age (Fig. 2B) although this relationship was not significant (Table 2) while both IgM directed against Plasmodium total schizont and total $\mathrm{IgG}$ directed against MSP-2(CH150) declined with host age (Fig. 2B, Table 2). There were differences in the levels of parasite-specific responses mounted by children resident in the different villages. The majority of schistosome-specific responses were higher in Magaya (high infection area) compared to Chitate 
Table 2. Analysis of variance $\mathrm{F}$ and $(\mathrm{P})$ values of the factors affecting parasite-specific antibody levels and systemic cytokines

\begin{tabular}{|c|c|c|c|c|c|c|c|}
\hline & $\begin{array}{l}\text { Antibody/ } \\
\text { Cytokine }\end{array}$ & Antigen & Sex & Age-group & Village & $\begin{array}{l}\text { Infection } \\
\text { status }\end{array}$ & $\begin{array}{l}\text { Village*Age } \\
\text { group } \\
\text { interaction }\end{array}$ \\
\hline \multirow[t]{9}{*}{ S. haematobium } & \multirow[t]{3}{*}{$\operatorname{IgM}$} & CAP & $0 \cdot 35(0 \cdot 70)$ & $0 \cdot 87(0 \cdot 42)$ & $0 \cdot 37(0 \cdot 54)$ & $1 \cdot 27(0 \cdot 26)$ & $1 \cdot 42(0 \cdot 25)$ \\
\hline & & SEA & $0 \cdot 11(0 \cdot 89)$ & $0 \cdot 43(0 \cdot 65)$ & $0 \cdot 28(0 \cdot 60)$ & $2 \cdot 36(0 \cdot 13)$ & $0 \cdot 06(0 \cdot 94)$ \\
\hline & & WWH & $1 \cdot 17(0 \cdot 32)$ & $5 \cdot 17(0 \cdot 009)$ & $15 \cdot 37(<0 \cdot 001)$ & $1 \cdot 46(0 \cdot 23)$ & $0 \cdot 19(0 \cdot 83)$ \\
\hline & \multirow[t]{3}{*}{$\operatorname{IgE}$} & CAP & $0 \cdot 72(0 \cdot 49)$ & $1 \cdot 77(0 \cdot 18)$ & $13 \cdot 25(0 \cdot 001)$ & $0 \cdot 97(0 \cdot 33)$ & $0 \cdot 56(0 \cdot 57)$ \\
\hline & & SEA & $0 \cdot 12(0 \cdot 89)$ & $1 \cdot 37(0 \cdot 26)$ & $1 \cdot 70(0 \cdot 20)$ & $0 \cdot 39(0 \cdot 54)$ & $3 \cdot 27(0 \cdot 05)$ \\
\hline & & WWH & $0 \cdot 15(0 \cdot 87)$ & $0 \cdot 004(0 \cdot 996)$ & $2 \cdot 30(0 \cdot 14)$ & $0 \cdot 67(0 \cdot 42)$ & $1 \cdot 11(0 \cdot 34)$ \\
\hline & \multirow[t]{3}{*}{ IgG4 } & CAP & $1 \cdot 46(0 \cdot 21)$ & $3 \cdot 18(0 \cdot 05)$ & $0 \cdot 96(0 \cdot 33)$ & $1 \cdot 74(0 \cdot 19)$ & $0 \cdot 42(0 \cdot 66)$ \\
\hline & & SEA & $1 \cdot 99(0 \cdot 15)$ & $1 \cdot 08(0 \cdot 35)$ & $2 \cdot 41(0 \cdot 13)$ & $8 \cdot 52(0 \cdot 005)$ & $3 \cdot 08(0 \cdot 05)$ \\
\hline & & WWH & $0 \cdot 01(0 \cdot 99)$ & $0 \cdot 96(0 \cdot 39)$ & $6 \cdot 59(0 \cdot 013)$ & $3 \cdot 40(0 \cdot 07)$ & $1 \cdot 05(0 \cdot 36)$ \\
\hline \multirow[t]{5}{*}{ P. falciparum } & $\operatorname{IgM}$ & $\mathrm{TSz}$ & $0 \cdot 95(0 \cdot 31)$ & $4 \cdot 28(0 \cdot 018)$ & $66 \cdot 56(<0 \cdot 001)$ & $2 \cdot 86(0 \cdot 10)$ & $0 \cdot 42(0 \cdot 66)$ \\
\hline & \multirow[t]{4}{*}{ IgG } & $\mathrm{TSz}$ & $0 \cdot 80(0 \cdot 45)$ & $1 \cdot 56(0 \cdot 21)$ & $29 \cdot 87(<0 \cdot 001)$ & $1 \cdot 85(0 \cdot 18)$ & $0 \cdot 55(0 \cdot 58)$ \\
\hline & & MSP-1 19 & $0 \cdot 90(0 \cdot 41)$ & $0 \cdot 83(0 \cdot 43)$ & $0 \cdot 19(0 \cdot 67)$ & $0 \cdot 11(0 \cdot 74)$ & $0 \cdot 77(0 \cdot 47)$ \\
\hline & & $\begin{array}{l}\text { MSP-2 } \\
(\mathrm{CH} 150)\end{array}$ & $0 \cdot 90(0 \cdot 41)$ & $14 \cdot 21(<0 \cdot 001)$ & $76 \cdot 64(<0 \cdot 001)$ & $0 \cdot 34(0 \cdot 56)$ & $0 \cdot 83(0 \cdot 44)$ \\
\hline & & MSP-2(dD2) & $0 \cdot 45(0 \cdot 62)$ & $0 \cdot 03(1)$ & $1 \cdot 67(0 \cdot 20)$ & $4 \cdot 49(0 \cdot 038)$ & $0 \cdot 79(0 \cdot 46)$ \\
\hline \multirow[t]{5}{*}{ Cytokines } & IFN- $\gamma$ & & $0 \cdot 22(0 \cdot 64)$ & $0 \cdot 87(0 \cdot 42)$ & $0 \cdot 04(0 \cdot 84)$ & $1 \cdot 71(0 \cdot 20)$ & $0 \cdot 06(0 \cdot 95)$ \\
\hline & TNF- $\alpha$ & & $1 \cdot 38(0 \cdot 25)$ & $1 \cdot 25(0 \cdot 29)$ & $0 \cdot 17(0 \cdot 68)$ & $0 \cdot 23(0 \cdot 63)$ & $0 \cdot 35(0 \cdot 71)$ \\
\hline & IL-4 & & $3 \cdot 97(0 \cdot 06)$ & $2 \cdot 29(0 \cdot 11)$ & $23 \cdot 3(<0 \cdot 001)$ & $0 \cdot 86(0 \cdot 36)$ & $5 \cdot 04(0 \cdot 01)$ \\
\hline & IL-5 & & $0 \cdot 1(0 \cdot 96)$ & $0 \cdot 15(0 \cdot 86)$ & $0 \cdot 02(0 \cdot 89)$ & $1 \cdot 51(0 \cdot 22)$ & $0 \cdot 11(0 \cdot 90)$ \\
\hline & IL-10 & & $5 \cdot 23(0 \cdot 026)$ & $2 \cdot 2(0 \cdot 12)$ & $0 \cdot 23(0 \cdot 63)$ & $0 \cdot 91(0 \cdot 34)$ & $0 \cdot 78(0 \cdot 46)$ \\
\hline
\end{tabular}

Schistosome-specific antibody levels were measured against cercariae (CAP), adult worm (WWH) and egg (SEA) antigens. Plasmodium antigens were measured against total schizont (Tsz) and the recombinant proteins Merozoite Surface protein (MSP)-1 19 , MSP-2(CH150) and MSP-2(dD2). $P$ values significant at $P<0 \cdot 05$ are highlighted in bold.

(low infection area) ('Table 2). Only anti-worm IgG4 responses were higher in Chitate compared to Magaya. The converse was true for anti-Plasmodium responses, with the difference being significant only for responses against the schizont and MSP-2 (CH150). Having allowed for the effects of sex, age and village of residence, the relationship between infection intensity and antibody levels was tested. This showed that levels of all anti-schistosome antibodies were higher in egg positive children compared to egg negative children and the converse was true for Plasmodium-specific responses (Table 2). The relationship was significant only for anti-schistosome egg IgG4 and anti-Plasmodium MSP-2(Dd2). The interaction between village and age group had a significant effect on anti-schistosome egg $\operatorname{IgE}$ and $\operatorname{IgG} 4$, showing that the development of these responses with host age differ between the two villages.

\section{Relationship between exposure and acquired immunity}

Factor analysis reduced, all of the 9 schistosomespecific immune responses to 3 components shown in Table 3. The first component $S h$-PC1 accounting for the highest variance was composed of all the antischistosome $\operatorname{IgM}$ responses and anti-egg $\operatorname{IgE}$ and IgG4. This component reflected exposure to schistosome antigens and was significantly associated with schistosome infection intensity, being higher in egg positive children after allowing for host sex, age and village ('Table 4A). The second component $S h$ PC2was composed of $\mathrm{IgE}$ directed against cercariae, previously shown to be associated with hypersensitivity in the skin. The only factor affecting levels of this component was village, with people in the low infection area having significantly higher levels than people residing in the high infection area. However, this component was significantly correlated with levels of $S h$-PC1 after controlling for age, sex, village, or schistosome infection (Table 4B). The last component $S h$-PC3 was made up of anti-worm IgE and IgG4. Anti-worm IgE was negatively loaded in component 3 , implying an inverse relationship with anti-worm IgG4 (Table 4A). Thus low scores for this component are analogous to an increase in the adult worm-specific $\operatorname{IgE}: \operatorname{IgG} 4$ ratio, which is associated with development of resistance to schistosome infection. Sh-PC3 was not significantly associated with host sex, age, village of residence or schistosome infection (Table 4A) but was positively correlated with the first component Sh-PC1 ('Table 4B).

The five anti-Plasmodium antibody responses reduced to 2 principal components (Table 5), the first component, (Pf-PC1) explaining $42 \%$ of the variation was made up of the anti-schizont responses and anti MSP-2(Dd2) responses. These responses are indicative of exposure to Plasmodium schizont antigens and these responses declined significantly with 
A

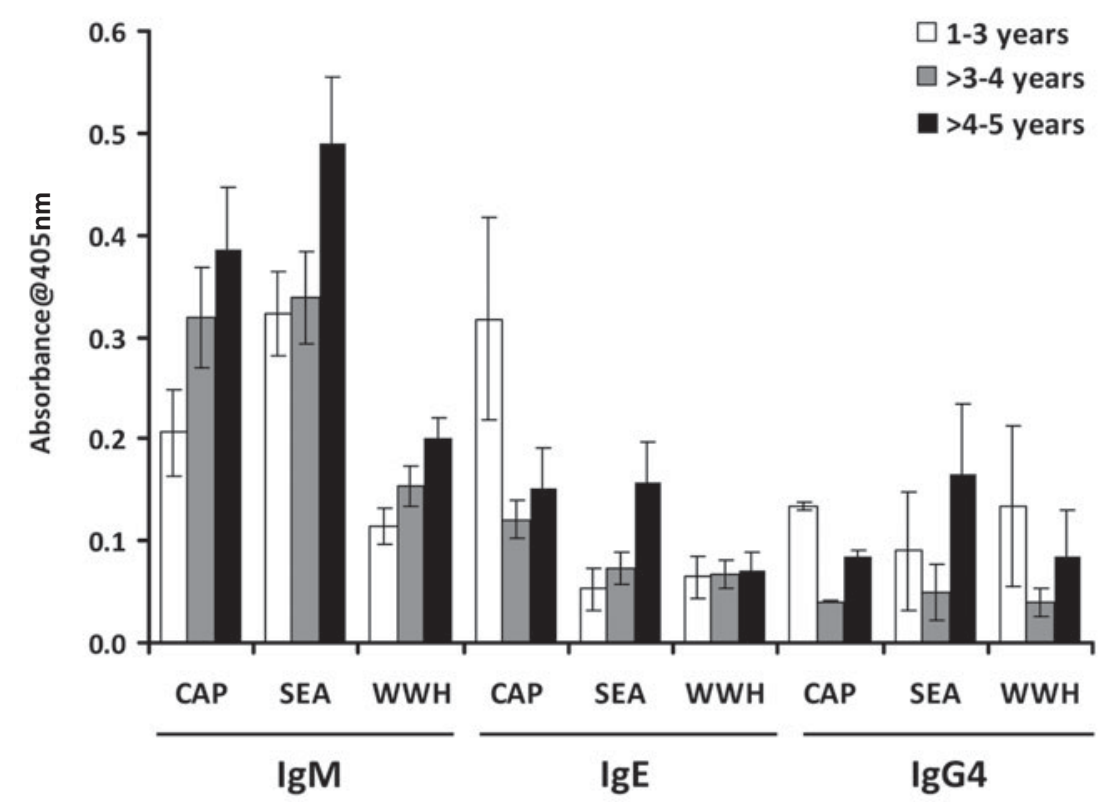

B

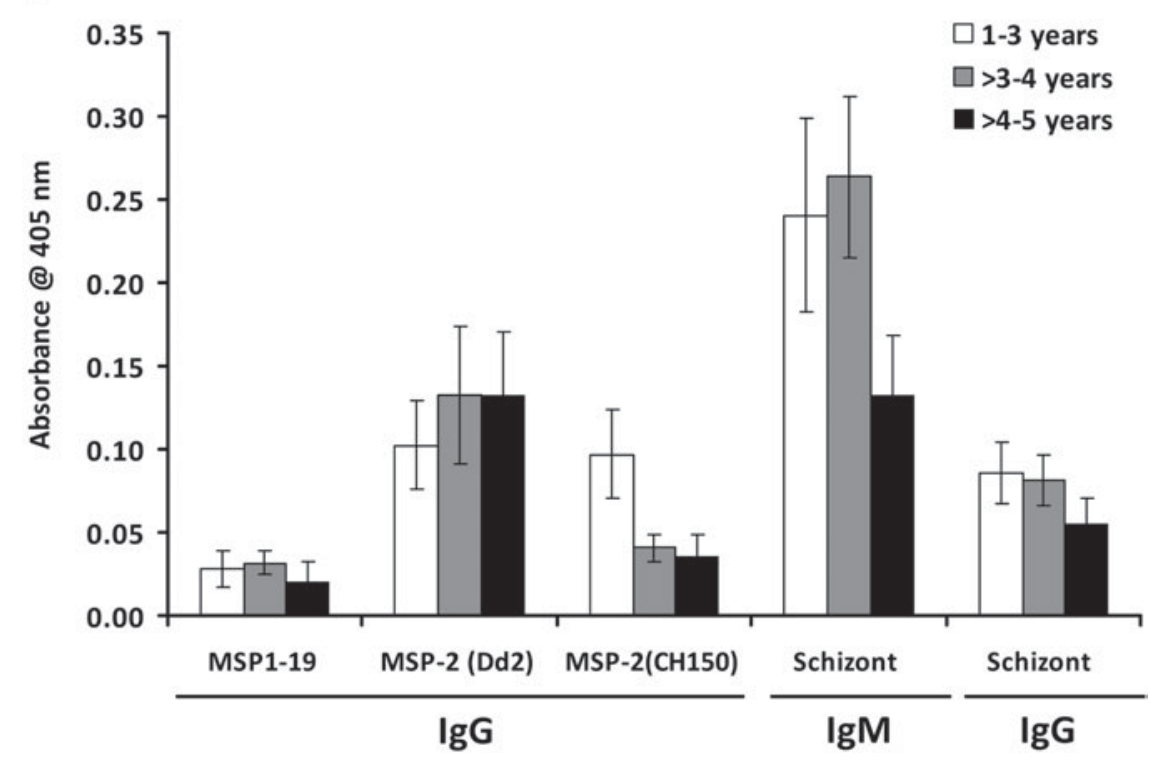

Fig. 2. Parasite specific age-antibody profiles. Open bars $=1-3$ years old, grey bars $=3>$ to 4 years, black bars $=4>$ to 5 years. Standard error of the mean is shown for each bar. (A) Schistosoma haematobium -specific responses $(\mathrm{CAP}=$ cercariae antigen preparation, $\mathrm{SEA}=$ soluble egg antigen, $\mathrm{WWH}=$ soluble adult worm antigen preparation. (B) Plasmodium falciparum-specific responses (MSP = Merozoite Surface Protein).

age (Table 4A). Furthermore, these responses were significantly higher in Chitate, the low schistosome infection area but had no relationship to schistosome infection or host sex. Anti-MSP-1 19 and MSP-2 (CH150) responses were grouped in component 2 (Pf-PC2), which explained $24 \%$ of the variation. These responses are indicative of the development of immunity against Plasmodium infection and were not related to host age, sex, village, or schistosome infection. However, they were negatively correlated to the $P f$-PC1 responses after controlling for the effects of age, sex, village and schistosome infection (Table 4B).

\section{Cytokine responses}

To allow direct comparisons between cytokines, the number of people with detectable systemic cytokine levels was determined and compared rather than the absolute values (absolute levels of cytokines varied on different scales with IL-4 and IFN- $\gamma$ levels being in $\mathrm{ng} / \mathrm{ml}$ while levels of IL-10 were in $\mathrm{pg} / \mathrm{ml}$ ). Most participants had detectable levels of IL-10, followed by IL-4 with the least number of participants having detectable TNF- $\alpha$ (Fig. 3A). Only 2 children (both 5 years of age, one positive for schistosome eggs and the other negative) had detectable levels of all 
Table 3. Principal components extracted for schistosome-specific responses

\begin{tabular}{|c|c|c|c|}
\hline & \multicolumn{3}{|c|}{ S. haematobium component } \\
\hline & $\begin{array}{l}\text { PC1- Schistosome } \\
\text { exposure }(S h-P C 1)\end{array}$ & $\begin{array}{l}\text { PC2-Anti- } \\
\text { schistosome } \\
\text { egg and cercariae } \\
\text { responses }(S h-\mathrm{PC} 2)\end{array}$ & $\begin{array}{l}\text { PC3-Adult-worm- } \\
\text { specific immunity } \\
(S h-P C 3)\end{array}$ \\
\hline & $\begin{array}{l}\text { Accounts for } 36 \% \text { of } \\
\text { total variation }\end{array}$ & $\begin{array}{l}\text { Accounts for } 16 \% \text { of } \\
\text { total variation }\end{array}$ & $\begin{array}{l}\text { Accounts for } 12 \% \text { of } \\
\text { total variation }\end{array}$ \\
\hline CAP IgM & $0 \cdot 879$ & $-0 \cdot 128$ & $0 \cdot 173$ \\
\hline SEA IgM & 0.785 & $-0 \cdot 222$ & $0 \cdot 071$ \\
\hline WWH IgM & $0 \cdot 833$ & $-0 \cdot 235$ & $0 \cdot 023$ \\
\hline CAP IgE & $0 \cdot 355$ & $0 \cdot 779$ & $0 \cdot 008$ \\
\hline SEA IgE & $0 \cdot 646$ & $0 \cdot 564$ & $0 \cdot 036$ \\
\hline WWH IgE & $0 \cdot 101$ & $0 \cdot 409$ & $-0 \cdot 728$ \\
\hline CAP IgG4 & $0 \cdot 469$ & $-0 \cdot 328$ & $-0 \cdot 141$ \\
\hline SEA IgG4 & $0 \cdot 637$ & $0 \cdot 008$ & $-0 \cdot 019$ \\
\hline $\begin{array}{l}\text { WWH } \\
\text { IgG4 }\end{array}$ & $0-0 \cdot 138$ & $0 \cdot 367$ & $0 \cdot 731$ \\
\hline
\end{tabular}

Schistosome-specific antibody levels were measured against cercariae (CAP), adult worm (WWH) and egg (SEA) antigens. The loading value of each antibody for each principal component $(\mathrm{PC})$ are given with variables with strong loadings $(0 \cdot 6$ or $<-0 \cdot 6)$ are indicated in bold.

Table 4A. Analysis of variance $\mathrm{F}$ and $(\mathrm{P})$ values of the factors affecting parasite exposure and immune responses

\begin{tabular}{|c|c|c|c|c|c|}
\hline & & Age-group & Village & $\begin{array}{l}\text { Infection } \\
\text { intensity }\end{array}$ & $\begin{array}{l}\text { Village* } \\
\text { age group }\end{array}$ \\
\hline Sh-PC1 (exposure to schistosome infection) & $0 \cdot 9(0 \cdot 41)$ & $1 \cdot 02(0 \cdot 37)$ & $3 \cdot 25(0 \cdot 08)$ & $10 \cdot 04(0 \cdot 002)$ & $0 \cdot 67(0 \cdot 52)$ \\
\hline Sh-PC2 (cercariae-pecific IgE responses) & $1 \cdot 68(0 \cdot 20)$ & $1 \cdot 98(0 \cdot 15)$ & $13 \cdot 57(0 \cdot 001)$ & $0 \cdot 01(0 \cdot 922)$ & $2 \cdot 16(0 \cdot 13)$ \\
\hline Sh-PC3 (adult worm-specific IgE) & $0 \cdot 12(0 \cdot 89)$ & $0 \cdot 30(0 \cdot 74)$ & $0 \cdot 02(0 \cdot 88)$ & $0 \cdot 31(0 \cdot 58)$ & $0 \cdot 70(0 \cdot 50)$ \\
\hline Pf-PC1 (exposure to Plasmodium infection) & $0 \cdot 85(0 \cdot 43)$ & $4 \cdot 07(0 \cdot 02)$ & $56 \cdot 0(P<0 \cdot 001)$ & $1 \cdot 05(0 \cdot 31)$ & $0 \cdot 16(0 \cdot 84)$ \\
\hline Pf-PC2 (Immunity against Plasmodium) & $0 \cdot 85(0 \cdot 43)$ & $0 \cdot 27(0 \cdot 76)$ & $0.53(0.47)$ & $0 \cdot 13(0 \cdot 72)$ & $1 \cdot 02(0 \cdot 37)$ \\
\hline Cytokine-PC (systemic cytokines) & $1 \cdot 85(0 \cdot 18)$ & $1 \cdot 13(0 \cdot 33)$ & $2 \cdot 76(0 \cdot 10)$ & $3 \cdot 97(0 \cdot 05)$ & $0 \cdot 60(0 \cdot 55)$ \\
\hline
\end{tabular}

Factors significant at $P<0.05$ are highlighted in bold.

Table 4B. Relationship between parasite-specific antibody levels and systemic cytokines

\begin{tabular}{|c|c|c|c|c|c|}
\hline & $S h-\mathrm{PC} 1$ & $S h-\mathrm{PC} 2$ & Sh-PC3 & $P f-\mathrm{PC} 1$ & $P f$-PC2 \\
\hline Sh-PC1 (exposure to schistosome infection) & - & & & & \\
\hline$S h-\mathrm{PC} 2$ (cercariae-specific IgE responses) & $0.33(0.02)$ & - & & & \\
\hline Sh-PC3 (adult worm-specific IgE) & $0 \cdot 01(0 \cdot 315)$ & $-0 \cdot 22(0 \cdot 08)$ & - & & \\
\hline Pf-PC1 (exposure to Plasmodium infection) & $0 \cdot 20(0 \cdot 09)$ & $-0 \cdot 96(0 \cdot 27)$ & $-0 \cdot 17(0 \cdot 14)$ & - & \\
\hline Pf-PC2 (Immunity against Plasmodium) & $-0 \cdot 191(0 \cdot 11)$ & $0 \cdot 03(0 \cdot 42)$ & $0 \cdot 19(0 \cdot 11)$ & $-0 \cdot 34(0 \cdot 01)$ & - \\
\hline Cytokine-PC (systemic cytokines) & $0 \cdot 21(0 \cdot 08)$ & $0 \cdot 28(0 \cdot 04)$ & $-0 \cdot 17(0 \cdot 13)$ & $-0 \cdot 03(0 \cdot 42)$ & $-0 \cdot 04(0 \cdot 39)$ \\
\hline
\end{tabular}

Partial correlation (controlling for host sex, age, village and schistosome infection intensity) r-values and $(P)$ values. Correlations significant at $P<0.05$ are highlighted in bold.

5 cytokines. The proportion of children producing each cytokine did not vary significantly with host age, sex, and village or schistosome infection. When the effects of host sex, age, village and schistosome infection on the concentrations of each cytokine was assessed, sex was found to significantly affect levels of IL-10, with females having higher levels than males.
The relationship between IL-4 and age was also found to differ between the two villages (Table 2).

Factor analysis reduced all the cytokines into a single variable (Table 6) composed of IL-5, IL-10 and IFN $-\gamma$. Levels of this cytokine PC rose significantly with age and were positively correlated with schistosome infection (Table 4A) and the 
Table 5. Principal components extracted for Plasmodium-specific responses

\begin{tabular}{|c|c|c|}
\hline & \multicolumn{2}{|l|}{$P$. falciparum component } \\
\hline & $\begin{array}{l}\text { PC1-Exposure to } \\
\text { Plasmodium falciparum } \\
(P f \text {-PC1) }\end{array}$ & $\begin{array}{l}\text { PC2-Immunity agains } \\
\text { Plasmodium falciparum } \\
\text { (Pf-PC2) }\end{array}$ \\
\hline & $\begin{array}{l}\text { Accounts for } 42 \% \\
\text { of total variation }\end{array}$ & $\begin{array}{l}\text { Accounts for } 24 \% \\
\text { of total variation }\end{array}$ \\
\hline MSP-1 $_{19}$ IgG & $0 \cdot 263$ & -0.667 \\
\hline MSP-2(Dd2) IgG & $0 \cdot 049$ & 0.735 \\
\hline MSP-2(CH150) IgG & $0 \cdot 627$ & $0 \cdot 445$ \\
\hline Tsz IgM & 0.903 & $-0 \cdot 110$ \\
\hline Tsz IgG & 0.900 & $-0 \cdot 045$ \\
\hline
\end{tabular}

Plasmodium antigens were measured against total schizont (Tsz) and the recombinant proteins Merozoite Surface protein (MSP)-1 $1_{19}$, MSP-2(CH150) and MSP-2(dD2). The loading value of each antibody for each principal component $(\mathrm{PC})$ are given with variables with strong loadings $(0 \cdot 6$ or $-0 \cdot 6)$ are indicated in bold.

A

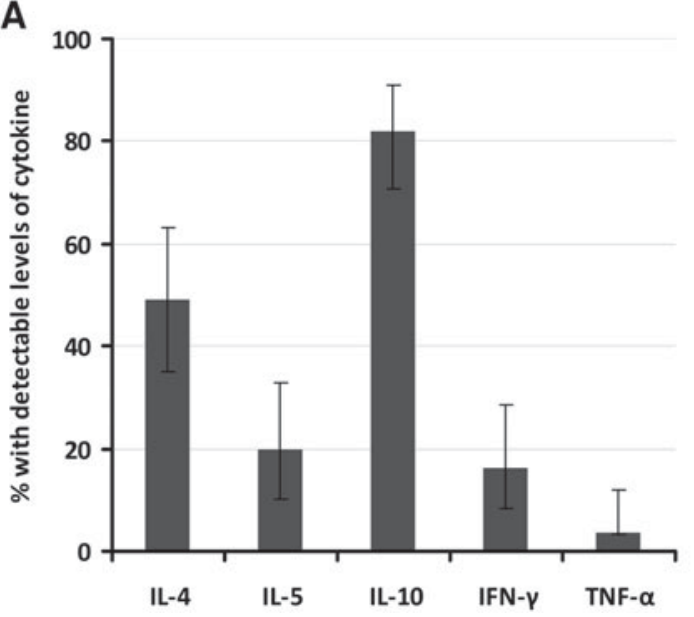

B

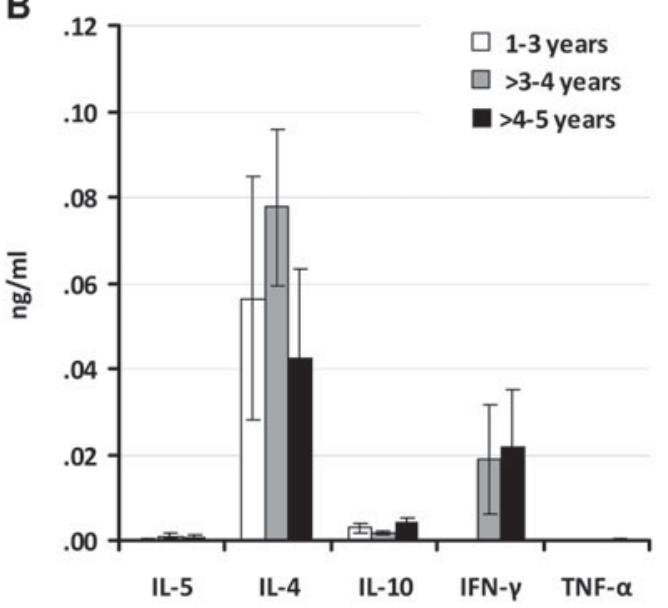

Fig. 3. Systemic levels of the cytokines. (A) Percentage of people with detectable cytokine levels in their plasma with 95\% confidence interval shown. (B) Age-profile for each cytokine. Open bars $=1-3$ years old, grey bars $=3>$ to 4 years, black bars $=4>$ to 5 years. Standard error of the mean is shown for each bar.

schistosome-specific hypersensitivity responses in Sh-PC2 (Table 4B) after controlling for host age, sex, village or schistosome infection.

\section{DISCUSSION}

The geographical and demographical co-distribution of Schistosoma haematobium and Plasmodium falciparum in Africa means that young children can be coinfected with both parasites. Despite this overlap, the burden of these co-infections in children aged 5 years and under is relatively less studied than in children aged 6 years and above. Furthermore, there is a paucity of studies characterizing the nature and development of parasite-specific immune responses to these parasites in children aged 5 years and below. Therefore we set out to (1) determine the prevalence and intensity of infection and co-infection with these parasites in children aged 1-5 years resident in a schistosome and Plasmodium endemic area; (2) determine levels of exposure detected as the presence of serum antibodies specific for one or both parasites and, (3) characterize systemic immune responses (cytokine and parasite-specific antibody) in these young children. By conducting the study in two villages of different schistosome infection levels, the effect of different schistosome transmission dynamics on immune responses could be compared.

In this study, the overall schistosome infection prevalence was $14 \cdot 7 \%$ by egg count, with a significant difference between the two areas. Prevalence in the high infection area was $23 \%$ and $3 \%$ in low infection area. These levels were slightly lower than those diagnosed by the presence of anti-egg antibodies $(16 \cdot 7 \%$ overall and $24 \cdot 4 \%$ in Magaya and $7 \cdot 7 \%$ in Chitate), consistent with a recent report from a study in 
Table 6. Principal components extracted for systemic cytokine levels

\begin{tabular}{lc}
\hline \hline & Cytokine PC \\
\cline { 2 - 2 } & $\begin{array}{l}\text { Accounts for } 40 \% \\
\text { of total variation }\end{array}$ \\
\hline IL-4 & $-0 \cdot 377$ \\
IL-5 & $\mathbf{0 \cdot 7 8 0}$ \\
IL-10 & $\mathbf{0 \cdot 6 7 4}$ \\
IFN- $\gamma$ & $\mathbf{0 \cdot 6 5 2}$ \\
TNF- $\alpha$ & $0 \cdot 587$ \\
\hline \hline
\end{tabular}

The loading value of each antibody for each principal component (PC) are given with variables with strong loadings $(0 \cdot 6$ or $-0 \cdot 6)$ are indicated in bold.

pre-school Ugandan children exposed to S. mansoni (Stothard et al. 2011) which showed that serological diagnosis gave slightly higher but not significantly different infection levels. In our study all egg-positive children were also serologically positive for schistosome infection although there were some egg-negative children who were positive for anti-egg antibodies. Not surprisingly, more children showed evidence of exposure to the infective stage of schistosomes, cercariae, with $43 \cdot 4 \%$ of the children producing anticercariae $\operatorname{IgM}(60 \%$ in the high infection area and $23.7 \%$ in the low infection area) than those that were positive for infection. The anti-cercariae responses indicated in part, pre-patent, single sex or low intensity infections which are not easily diagnosed by egg count methods (Stothard et al. 2011).

The youngest children showing evidence of exposure to cercariae antibodies were 3 years and 4 years in the high schistosome infection and low schistosome infection areas, respectively. This difference was consistent with the diagnosis of schistosome infection via microscopic egg counts with the youngest age at which children started excreting schistosome eggs in the urine, 3 years and 4 years and 6 months in the two areas, respectively. We have previously reported that, in areas of high $S$. haematobium infection, children as young as 4 months showed immunological evidence of exposure to schistosome cercariae (Woolhouse et al. 2000). Our current study indicates that, in areas of high schistosome infection, a large proportion of these young children are exposed to schistosome cercariae and that this exposure translates to patent infections in some cases.

The importance of these childhood schistosome infections is augmented by their potential interaction with other co-infections such as Plasmodium. Several studies have reported that co-infected children suffer parasite-related morbidity exacerbated by the presence of the other parasite (Remoue et al. 2003; Arinola, 2005; Wilson et al. 2008; Diallo et al. 2010). Conversely, there have been reports of a negative association between helminth infections and the severity of morbidity arising from Plasmodium infections (Nacher et al. 2000; Lyke et al. 2005). Experimental and human observational studies have indicated that the exacerbation of morbidity as well as negative association between helminth and Plasmodium infections has an immunological basis (Remoue et al. 2003; Arinola, 2005; Wilson et al. 2008; Diallo et al. 2010). In this current study, none of the children were positive for Plasmodium infection but $13 \cdot 4 \%$ of the children showed evidence of recent exposure to Plasmodium schizonts. It is unlikely that this IgM response was related to maternal exposure to Plasmodium parasites since the youngest child with anti-schizont levels above those of the controls was 4 years old. All children showing immunological evidence of exposure to the schizonts were resident in the low schistosome infection area; the reasons for this are unclear. Both study areas are mesoendemic for Plasmodium infection but the differences in temporal patterns of the rivers in the two areas that affect the schistosome transmission dynamics may affect the breeding sites for the Plasmodium mosquito vector. There was no association between schistosome-specific and Plasmodium-specific immune responses in either village. This is possibly due to the low level of Plasmodium endemicity in the area. Thus, the interactions reported from the other studies where both the Plasmodium transmission and the incidence of clinical malaria is higher may be influenced by current levels of parasitaemia experienced by the children as well as their history of infection with both parasites. We have previously reported an interaction between schistosome-specific antibodies and $P$. falciparum from older Zimbabwean children resident in higher transmission areas for both parasites (Mutapi et al. 2000, 2007a).

Immune responses against schistosomes and those against Plasmodium parasites show distinct age profiles (Mutapi et al. 1997; Mutapi et al. 2007b; Iriemenam et al. 2009). In population studies including children aged 6 years and above, schistosome infection intensity, $\mathrm{IgM}$ and total $\mathrm{IgG}$ antibodies follow the typical convex age-infection curve originally described for schistosome infections by Fisher in 1934 (Fisher, 1934), i.e. they rise with age peaking in older children and then decline in adulthood. This age-profile for IgM and total $\mathrm{IgG}$ is largely a result of age-related exposure patterns to infective water as well as egg and adult worm antigens (Ndhlovu et al. 1996; Mutapi et al. 1997). Unlike IgM and total IgG, levels of IgE levels with age (Dunne et al. 1992; Mutapi et al. 1997) and the ratio of $\operatorname{IgE}: \operatorname{IgG} 4$, which has been associated with the development of resistance to infection/re-infection in $S$. haematobium infections, also increases with age. This study showed that these age-related patterns can already be detected in children under 6 years of age. IgM levels directed against all parasite stages rose with age consistent with age-related increases in exposure to infective 
water (Woolhouse et al. 2000). Furthermore, IgM levels rose more quickly with age in the high infection area consistent with the existence of peak shifts in antibody levels in areas of different schistosome infections (Mutapi et al. 1997). Schistosome-specific antibody responses were higher in Magaya, the high schistosome infection area compared to Chitate the low infection area. This is not surprising as previously studies have indicated that in the early age groups schistosome specific responses are correlated to the levels of the infections that are stimulating them (Ndhlovu and Woolhouse, 1996; Mutapi et al. 1997). IgE responses directed against cercariae were significantly higher in the low infection area compared to the high infection area and they declined with age (although this was not significant) which would be consistent with a reduction in acute immune hyperactivity to cercarial exposure (swimmers' itch) (Cort, 1928; Kourilova et al. 2004) mediated by $\operatorname{IgE}$ antibodies which is observed in residents of schistosome-endemic areas. This suggests that by the time these children start school (the youngest age-group normally enrolled in schistosome immuno-epidemiology studies) the early anticercariae responses are already different from those observed at first exposure. Thus in this study the immune responses which are associated with exposure to the parasite antigens are significantly related to schistosome infection. However, immune responses associated with protection to adult schistosomes did not follow distinct patterns with infection. Similar to Plasmodium infections, acquired immunity to schistosomes takes several years to develop to levels sufficient to have observed effects on levels of infection/re-infection (Langhorne et al. 2008; Woolhouse et al. 1991).

The Plasmodium antibody responses in these children were reduced into two variables composed of responses directed against the crude antigens and MSP-2(CH150) and those directed against MSP-1 19 and MSP-2(Dd2) suggesting that these variables were representative of distinct biological processes associated with putative exposure to parasites (Naus et al.2003b) and the development of protective acquired immunity respectively (Conway et al. 2000; Mawili-Mboumba et al. 2003; Metzger et al. 2003; Polley et al. 2003, 2006; Cavanagh et al. 2004). These responses were negatively correlated and Plasmodium-specific responses indicative of exposure to parasite antigens declining significantly with age (after controlling for variation to host sex, village, and schistosome infection). Unlike anti-schistosome antibody responses, levels of antibodies to several Plasmodium antigens may vary with the seasonality of parasite transmission, often being higher during periods of high transmission than at the end of a low transmission season (Cavanagh et al. 1998). Furthermore, levels of anti-Plasmodium antibodies tend to be higher in individuals carrying patent parasite infections than in those without parasites at the time of the survey for both crude antigens and recombinant antigens such as the vaccine candidates we studied here (Polley et al. 2006; Osier et al. 2008). Isotype switching after $\mathrm{B}$ cell activation and the absence of IgM memory responses also means that levels of circulating anti-Plasmodium IgM responses decline in favour of a switch to IgG3 responses typically observed in children (Taylor et al. 1998). Therefore it is not surprising that immune responses indicative of recent exposure decline with age and responses associated with resistance to Plasmodium did not show distinct patterns with age as these are still developing.

Systemic cytokines were detected in most children, with IL-10 being the most prevalent within the cohort, despite being present at low concentrations compared to the other cytokines. This is consistent with results we have previously reported from Zimbabwean populations showing that levels of both schistosome-specific and systemic IL-10 were low compared to the other cytokines (Mutapi et al. 2007b; Milner et al. 2010). The high prevalence of IL-10 may be related to its role in isotype switching to IgG subclasses (Garraud et al. 2003) and its regulatory function modulating both Th1 and Th2 responses (Hunt and Grau, 2003). The least detected cytokines were TNF- $\alpha$ and IFN- $\gamma$, which are associated with inflammatory Th1-type responses. The cytokine responses rose with schistosome specific anti-egg responses and schistosome infection. We have previously demonstrated that systemic IL-5 and IL-4 were correlated with low S. haematobium infection in putatively resistant individuals (i.e. lifelong residents of schistosome-endemic areas who, despite continued exposure to infective water, harbour little or no schistosome infection) (Milner et al. 2010). In human Plasmodium infections elevated levels of both IFN- $\gamma$ and TNF- $\alpha$ are associated with severe malaria (Awandare et al. 2006) so that their presence in children concurrently exposed to helminth and Plasmodium infections might be expected to exacerbate Plasmodium-related pathology. Conversely, low IL-10 plasma levels are associated with severe malarial anemia (Kurtzhals et al. 1998). IL-5 and IL-10 are associated with protection against re-infection with schistosomes (Medhat et al. 1998; Abath et al. 2006). However, there were no significant associations between plasma cytokines and Plasmodium-specific antibody levels. This suggests that either the plasma cytokines reflect current parasitic infections which is consistent with the significant association between the systemic cytokine levels and schistosome infection, or, that the dynamics of parasite-specific and systemic cytokine differ in this context.

Overall this study has shown that, in both areas of high and low schistosome infection, children aged 5 years and below show immunological evidence of exposure to schistosome infection. In areas of high 
schistosome infection, a large proportion of children aged 5 years and below was excreting schistosome eggs. Furthermore, the children also show immunological evidence of exposure to Plasmodium although none of them were positive for Plasmodium infection. Both schistosome-specific and Plasmodium-specific responses associated with protection to infection/reinfection were detected in the children together with a mixed systemic cytokine phenotype consisting of both Th1 and Th2 cytokines. The immune responses measured showed age-related patterns consistent with those reported in older children, suggesting that the development of protective acquired immunity starts in early childhood, although the effects of this immunity on infection levels and pathology may take time to become apparent.

\section{ACKNOWLEDGEMENTS}

We are grateful for the co-operation of the Ministry of Health and Child Welfare in Zimbabwe, the Provincial Medical Director of Mashonaland East, the Environmental Health Workers, and nursing staff at Chitate and Chitowa Clinics and Murehwa Hospital, residents, teachers and school children in Magaya, Chitate and Chipinda Schools. We also thank members of the National Institutes of Health in Zimbabwe and the Biochemistry Department at University of Zimbabwe for technical support. Finally we are grateful to the British Society for Parasitology for hosting the meeting on 'Progress in Paediatric Parasitology' where ideas presented in this manuscript were first presented.

\section{FINANCIAL SUPPORT}

This work was supported by the Carnegie Trust for the Universities of Scotland; Tenovus Scotland; University of Edinburgh Moray Endowment Fund; the World Health Organisation; and the Wellcome Trust (Grant no. WT082028MA)

\section{REFERENCES}

Abath, F. G., Morais, C. N., Montenegro, C. E., Wynn, T.A. and Montenegro, S. M. (2006). Immunopathogenic mechanisms in schistosomiasis: what can be learnt from human studies? Trends in Parasitology 22, 85-91.

Aribot, G., Rogier, C., Sarthou, J. L., Trape, J.F., Balde, A. T., Druilhe, P. and Roussilhon, C. (1996). Pattern of immunoglobulin isotype response to Plasmodium falciparum blood-stage antigens in individuals living in a holoendemic area of Senegal (Dielmo, west Africa). American fournal of Tropical Medicine and Hygiene 54, 449-457.

Arinola, O. G. (2005). Complement factors and circulating immune complexes in children with urinary schistosomiasis and asymptomatic malaria. African fournal of Medicine and Medical Sciences 34, 9-13.

Awandare, G. A., Goka, B., Boeuf, P., Tetteh, J. K., Kurtzhals, J. A., Behr, C. and Akanmori, B. D. (2006). Increased levels of inflammatory mediators in children with severe Plasmodium falciparum malaria with respiratory distress. Fournal of Infectious Diseases 194, 1438-1446.

Booth, M., Mwatha, J. K., Joseph, S., Jones, F. M., Kadzo, H., Ireri, E., Kazibwe, F., Kemijumbi, J., Kariuki, C., Kimani, G., Ouma, J. H., Kabatereine, N. B., Vennervald, B. J. and Dunne, D. W. (2004a). Periportal fibrosis in human Schistosoma mansoni infection is associated with low IL-10, low IFN-gamma, high TNF-alpha, or low RANTES, depending on age and gender. Fournal of Immunology 172, 1295-1303.

Booth, M., Vennervald, B. J., Butterworth, A.E., Kariuki, H. C., Amaganga, C., Kimani, G., Mwatha, J. K., Otedo, A., Ouma, J. H. and Dunne, D. W. (2004b). Exposure to malaria affects the regression of hepatosplenomegaly after treatment for Schistosoma mansoni infection in Kenyan children. BMC Medicine 2, 36.

Booth, M., Vennervald, B. J., Kabatereine, N. B., Kazibwe, F., Ouma, J.H., Kariuki, C.H., Muchiri, E., Kadzo, H., Ireri, E., Kimani, G., Mwatha, J. K. and Dunne, D. W. (2004c). Hepatosplenic morbidity in two neighbouring communities in Uganda with high levels of Schistosoma mansoni infection but very different durations of residence. Transactions of the Royal Society of Tropical Medicine and Hygiene 98, 125-136.

Bouharoun-Tayoun, H. and Druihle, P. (1992). Plasmodium falciparum: evidence for an isotype imbalance which may be responsible for delayed acquisition of protective immunity. Infection and Immunity 60, 1473-1481. Burghaus, P. A. and Holder, A. A. (1994). Expression of the 19-kilodalton carboxy-terminal fragment of the Plasmodium falciparum merozoite surface protein-1 in Escherichia coli as a correctly folded protein. Molecular and Biochemical Parasitology 64, 165-169.

Cavanagh, D. R., Dodoo, D., Hviid, L., Kurtzhals, J. A., Theander, T. G., Akanmori, B. D., Polley, S., Conway, D. J., Koram, K. and Mcbride, J. S. (2004). Antibodies to the N-terminal block 2 of Plasmodium falciparum merozoite surface protein 1 are associated with protection against clinical malaria. Infection and Immunity 72, 64926502 .

Cavanagh, D. R., Elhassan, I. M., Roper, C., Robinson, V. J., Giha, H., Holder, A. A., Hviid, L., Theander, T. G., Arnot, D. E. and Mcbride, J.S. (1998). A longitudinal study of type-specific antibody responses to Plasmodium falciparum merozoite surface protein-1 in an area of unstable malaria in Sudan. Fournal of Immunology 161, 347-359.

Cheesbrough, M. (1998). District Laboratory Practice in Tropical Countries. Part 1, Tropical Health Technology/Cambridge University Press, Cambridge.

Conway, D. J., Cavanagh, D. R., Tanabe, K., Roper, C., Mikes, Z. S., Sakihama, N., Bojang, K. A., Oduola, A. M., Kremsner, P. G., Arnot, D. E., Greenwood, B. M. and Mcbride, J. S. (2000). A principal target of human immunity to malaria identified by molecular population genetic and immunological analyses. Nature Medicine 6, 689-692.

Cort, W. W. (1928). Further observations on schistosome dermatitis in the United States (Michigan). Science 68, 388.

Del Prete, G., De Carli, M., Almerigogna, F., Giudizi, M. G., Biagiotti, R. and Romagnani, S. (1993). Human IL-10 is produced by both type 1 helper (Th1) and type 2 helper (Th2) T cell clones and inhibits their antigen-specific proliferation and cytokine production. Fournal of Immunology 150, 353-360.

Diallo, T. O., Remoue, F., Gaayeb, L., Schacht, A. M., Charrier, N., De Clerck, D., Dompnier, J. P., Pillet, S., Garraud, O., N'diaye, A. A. and Riveau, G. (2010). Schistosomiasis coinfection in children influences acquired immune response against Plasmodium falciparum malaria antigens. PLoS One 5, e12764.

Diallo, T. O., Remoue, F., Schacht, A.M., Charrier, N., Dompnier, J.P., Pillet, S., Garraud, O., N'diaye, A. A., Capron, A., Capron, M. and Riveau, G. (2004). Schistosomiasis co-infection in humans influences inflammatory markers in uncomplicated Plasmodium falciparum malaria. Parasite Immunology 26, 365-369.

Dunne, D. W., Butterworth, A.E., Fulford, A. J., Ouma, J. H. and Sturrock, R.F. (1992). Human IgE responses to Schistosoma mansoni and resistance to reinfection. Memorias do Instituto Oswaldo Cruz 87, 99-103.

Fisher, A. C. (1934). A study of schistosomiaisis in the Stanleyville district of Congo. Transactions of the Royal Society of Tropical Medicine and Hygiene 28, 277-306.

Garba, A., Barkire, N., Djibo, A., Lamin, E.S., Sofo, B., Gouvras, A. N., Bosque-Oliva, E., Webster, J.P., Stothard, J.P., Utzinger, J. et al. (2010). Schistosomiasis in infants and preschool-aged children: Infection in a single Schistosoma haematobium and a mixed S. haematobium-S. mansoni foci of Niger. Acta Tropica 115, 84-89.

Garraud, O., Mahanty, S. and Perraut, R. (2003). Malaria-specific antibody subclasses in immune individuals: a key source of information for vaccine design. Trends in Immunology 24, 30-35.

Hagan, P., Blumenthal, U. J., Dunne, D., Simpson, A. J. G. and Wilkins, A. H. (1991). Human IgE, IgG4 and resistance to reinfection with Schistosoma haematobium. Nature 349, 234-245.

Hay, S. I., Guerra, C. A., Gething, P. W., Patil, A. P., Tatem, A. J., Noor, A. M., Kabaria, C. W., Manh, B. H., Elyazar, I. R., Brooker, S., Smith, D. L., Moyeed, R. A. and Snow, R. W. (2009). A world malaria map: Plasmodium falciparum endemicity in 2007. PLoS Medicine 6, e1000048.

Hesse, M., Piccirillo, C. A., Belkaid, Y., Prufer, J., Mentink-Kane, M., Leusink, M., Cheever, A.W., Shevach, E. M. and Wynn, T. A. (2004). The pathogenesis of schistosomiasis is controlled by cooperating 
IL-10-producing innate effector and regulatory $\mathrm{T}$ cells. Journal of Immunolog $y$ 172, 3157-3166.

Holder, A. A., Blackman, M.J., Borre, M., Burghaus, P. A., Chappel, J. A., Keen, J. K., Ling, I. T., Ogun, S. A., Owen, C. A. and Sinha, K. A. (1994). Malaria parasites and erythrocyte invasion. Biochemical Society Transactions 22, 291-295.

Hunt, N. H. and Grau, G. E. (2003). Cytokines: accelerators and brakes in the pathogenesis of cerebral malaria. Trends in Immunology 24, 491-499.

Iriemenam, N.C., Okafor, C. M., Balogun, H. A., Ayede, I., Omosun, Y., Persson, J. O., Hagstedt, M., Anumudu, C. I., Nwuba, R. I., Troye-Blomberg, M. and Berzins, K. (2009). Cytokine profiles and antibody responses to Plasmodium falciparum malaria infection in individuals living in Ibadan, southwest Nigeria. African Health Science $\mathbf{9}$ 66-74.

Joseph, S., Jones, F. M., Kimani, G., Mwatha, J. K., Kamau, T., Kazibwe, F., Kemijumbi, J., Kabatereine, N. B., Booth, M., Kariuki, H. C., Ouma, J.H., Vennervald, B. J. and Dunne, D. W. (2004). Cytokine production in whole blood cultures from a fishing community in an area of high endemicity for Schistosoma mansoni in Uganda: the differential effect of parasite worm and egg antigens. Infection and Immunity 72, 728-734.

Katz, N., Chaves, A. and Pellegrino, J. (1972). A simple device for quantitative stool thick smear technique in schistosomiasis mansoni. Revista do Instituto de Medicina Tropical de Sao Paulo 14, 397-400.

Kourilova, P., Hogg, K. G., Kolarova, L. and Mountford, A. P. (2004) Cercarial dermatitis caused by bird schistosomes comprises both immediate and late phase cutaneous hypersensitivity reactions. Fournal of Immunology 172, 3766-3774

Kurtzhals, J. A., Adabayeri, V., Goka, B. Q., Akanmori, B. D. Oliver-Commey, J. O., Nkrumah, F. K., Behr, C. and Hviid, L. (1998). Low plasma concentrations of interleukin 10 in severe malarial anaemia compared with cerebral and uncomplicated malaria. Lancet 351, 1768-1772.

Langhorne, J., Ndungu, F. M., Sponaas, A. M. and Marsh, K. (2008). Immunity to malaria: more questions than answers. Nature Immunology $\mathbf{9}$ 725-732.

Lichtenbergova, L., Kolbekova, P., Kourilova, P., Kasny, M. Mikes, L., Haas, H., Schramm, G., Horak, P., Kolarova, L. and Mountford, A.P. (2008). Antibody responses induced by Trichobilharzia regenti antigens in murine and human hosts exhibiting cercarial dermatitis. Parasite Immunology 30, 585-595.

Lyke, K. E., Burges, R., Cissoko, Y., Sangare, L., Dao, M., Diarra, I., Kone, A., Harley, R., Plowe, C. V., Doumbo, O. K. and Sztein, M. B. (2004). Serum levels of the proinflammatory cytokines interleukin-1 beta (IL-1beta), IL-6, IL-8, IL-10, tumor necrosis factor alpha, and IL-12(p70) in Malian children with severe Plasmodium falciparum malaria and matched uncomplicated malaria or healthy controls. Infection and Immunity $\mathbf{7 2}$, 5630-5637.

Lyke, K. E., Dicko, A., Dabo, A., Sangare, L., Kone, A., Coulibaly, D. Guindo, A., Traore, K., Daou, M., Diarra, I., Sztein, M. B., Plowe, C. V. and Doumbo, O. K. (2005). Association of Schistosoma haematobium infection with protection against acute Plasmodium falciparum malaria in Malian children. American Fournal of Tropical Medicine and Hygiene 73, 1124-1130.

Mabaso, M. L., Craig, M., Vounatsou, P. and Smith, T. (2005). Towards empirical description of malaria seasonality in southern Africa: the example of Zimbabwe. Tropical Medicine and International Health 10, 909-918.

Mabaso, M. L., Vounatsou, P., Midzi, S., Da Silva, J. and Smith, T. (2006). Spatio-temporal analysis of the role of climate in inter-annual variation of malaria incidence in Zimbabwe. International Fournal of Health Geographics 5, 20.

Mafiana, C. F., Ekpo, U. F. and Ojo, D. A. (2003). Urinary schistosomiasis in preschool children in settlements around Oyan Reservoir in Ogun State, Nigeria: implications for control. Tropical Medicine and International Health 8(1):78-82.

Maitland, K. and Marsh, K. (2004). Pathophysiology of severe malaria in children. Acta Tropica 90, 131-140.

Maizels, R. M. and Yazdanbakhsh, M. (2003). Immune regulation by helminth parasites: cellular and molecular mechanisms. Nature Reviews Immunology 3, 733-744.

Malaquias, L.C., Falcao, P.L., Silveira, A. M., Gazzinelli, G., Prata, A., Coffman, R. L., Pizziolo, V., Souza, C.P., Colley, D. G. and Correa-Oliveira, R. (1997). Cytokine regulation of human immune response to Schistosoma mansoni: analysis of the role of IL-4, IL-5 and IL-10 on peripheral blood mononuclear cell responses. Scandinavian fournal of Immunology 46, 393-398.

Mawili-Mboumba, D.P., Borrmann, S., Cavanagh, D. R., Mcbride, J.S., Matsiegui, P.B., Missinou, M.A., Kremsner, P. G. and Ntoumi, F. (2003). Antibody responses to Plasmodium falciparum merozoite surface protein-1 and efficacy of amodiaquine in Gabonese children with $P$. falciparum malaria. Fournal of Infectious Diseases 187 1137-1141

Mckee, A. S. and Pearce, E. J. (2004). CD25 + CD4 + cells contribute to Th2 polarization during helminth infection by suppressing Th1 response development. Fournal of Immunology 173, 1224-1231.

Medhat, A., Shehata, M., Bucci, K., Mohamed, S., Dief, A. D., Badary, S., Galal, H., Nafeh, M. and King, C. L. (1998). Increased interleukin-4 and interleukin-5 production in response to Schistosoma haematobium adult worm antigens correlates with lack of reinfection after treatment. Fournal of Infectious Diseases 178, 512-519.

Metzger, W. G., Okenu, D. M., Cavanagh, D. R., Robinson, J. V., Bojang, K. A., Weiss, H. A., Mcbride, J.S., Greenwood, B. M. and Conway, D. J. (2003). Serum IgG3 to the Plasmodium falciparum merozoite surface protein 2 is strongly associated with a reduced prospective risk of malaria. Parasite Immunology 25, 307-312.

Mharakurwa, S., Mutambu, S.L., Mudyiradima, R. Chimbadzwa, T., Chandiwana, S. K. and Day, K.P. (2004). Association of house spraying with suppressed levels of drug resistance in Zimbabwe. Malaria fournal 3, 35.

Midzi, N., Mtapuri-Zinyowera, S., Mapingure, M. P., Sangweme, D., Chirehwa, M. T., Brouwer, K. C., Mudzori, J., Hlerema, G., Mutapi, F., Kumar, N. and Mduluza, T. (2010). Consequences of polyparasitism on anaemia among primary school children in Zimbabwe. Acta Tropica 115, 103-111.

Midzi, N., Sangweme, D., Zinyowera, S., Mapingure, M.P. Brouwer, K. C., Munatsi, A., Mutapi, F., Mudzori, J., Kumar, N., Woelk, G. and Mduluza, T. (2008). The burden of polyparasitism among primary schoolchildren in rural and farming areas in Zimbabwe. Transactions of the Royal Society of Tropical Medicine and Hygiene 102, 1039-1045.

Midzi, S., Teveredzi, V., Mudyiradima, R., Chihanga, S., Netsa, M., Mugove, A. T., Charimari, L., Pasipamire, J., Mutambu, S., Kibassa, C., Ngwenya, N., Gausi, K., Banda, J., Mukelabai, K., O'Connell, T. and Root, G. (2004). Roll Back Malaria Consultative Mission. Zimbabwe 2004. Available: http://www.rollbackmalaria.org/ patnership/country/docs/SAfrica/reaping_zimbabwe.pdf. Accessed 07 July 2011

Milner, T. M., Reilly, L.J., Nausch, N., Midzi, N., Mduluza, T., Maizels, R. M. and Mutap, F. (2010). Circulating cytokine levels and antibody responses to human Schistosoma haematobium: IL-5 and IL-10 levels depend upon age and infection status. Parasite Immunology.

Mott, K. E. (1983). A reusable polyamide filter for diagnosis of $S$. haematobium infection by urine filtration. Bulletin de la Societe de Pathologie Exotique 76, 101-104.

Mott, K. E. and Chen, M. G. (1989). Progress in assessment of morbidity due to Schistosoma haematobium infection, World Health Organisation, Geneva.

Mutapi, F., Burchmore, R., Foucher, A., Harcus, Y., Nicoll, G., Midzi, N., Turner, C. and Maizels, R. (2005). Praziquantel treatment of people exposed to Schistosoma haematobium enhances serological recognition of defined parasite antigens. Fournal of Infectious Diseases 192, 1108-1118.

Mutapi, F., Burchmore, R., Mduluza, T., Midzi, N., Turner, C. M. and Maizels, R. M. (2008). Age-related and infection intensity-related shifts in antibody recognition of defined protein antigens in a schistosomeexposed population. Fournal of Infectious Diseases 198, 167-175.

Mutapi, F., Hagan, P., Ndhlovu, P. and Woolhouse, M. E. J. (1997) Comparison of humoral responses to Schistosoma haematobium in areas with high and low levels of infection. Parasite Immunology 19, 255-263.

Mutapi, F., Ndhlovu, P. D., Hagan, P. and Woolhouse, M. E. J. (2000)

Anti-schistosome antibody responses in children coinfected with malaria. Parasite Immunology 22, 207-209.

Mutapi, F., Roussilhon, C., Mduluza, T. and Druilhe, P. (2007a). Antimalaria humoral responses in children exposed to Plasmodium falciparum and Schistosoma haematobium. Memorias do Instituto Oswaldo Cruz 102, 405-409.

Mutapi, F., Winborn, G., Midzi, N., Taylor, M., Mduluza, T. and Maizels, R. M. (2007b). Cytokine responses to Schistosoma haematobium in a Zimbabwean population: contrasting profiles for IFN-gamma, IL-4, IL-5 and IL-10 with age. BMC Infectious Diseases 7, 139

Nacher, M., Gay, F., Singhasivanon, P., Krudsood, S., Treeprasertsuk, S., Mazier, D., Vouldoukis, I. and Looareesuwan, S. (2000). Ascaris lumbricoides infection is associated with protection from cerebral malaria. Parasite Immunology 22, 107-113.

Naus, C. W., Jones, F.M., Satti, M.Z., Joseph, S., Riley, E. M., Kimani, G., Mwatha, J.K., Kariuki, C. H., Ouma, J.H., 
Kabatereine, N. B., Vennervald, B. J. and Dunne, D. W. (2003a). Serological responses among individuals in areas where both schistosomiasis and malaria are endemic: cross-reactivity between Schistosoma mansoni and Plasmodium falciparum. Fournal of Infectious Diseases 187, 1272-1282.

Naus, C. W., Van Remoortere, A., Ouma, J.H., Kimani, G., Dunne, D. W., Kamerling, J.P., Deelder, A. M. and Hokke, C. H. (2003b). Specific antibody responses to three schistosome-related carbohydrate structures in recently exposed immigrants and established residents in an area of Schistosoma mansoni endemicity. Infection and Immunity 71, 5676-5681.

Ndhlovu, P., Cadman, H., Vennervald, B. J., Christensen, N. O., Chidimu, N. and Chandiwana, S. K. (1996). Age-related antibody profiles in Schistosoma haematobium in a rural community in Zimbabwe. Parasite Immunology 18, 181-191.

Ndhlovu, P.D. and Woolhouse, M. E. J. (1996). Correlations between specific antibody-levels and urine egg counts for Schistosoma haematobium. Transactions of the Royal Society of Tropical Medicine and Hygiene 90, 324325 .

Oduro, A. R., Koram, K. A., Rogers, W., Atuguba, F., Ansah, P., Anyorigiya, T., Ansah, A., Anto, F., Mensah, N., Hodgson, A. and Nkrumah, F. (2007). Severe falciparum malaria in young children of the Kassena-Nankana district of northern Ghana. Malaria Fournal 6, 96.

Oeuvray, C., Bouharoun-Tayoun, H., Gras-Masse, H., Bottius, E., Kaidoh, T., Aikawa, M., Filgueira, M. C., Tartar, A. and Druilhe, P. (1994). Merozoite surface protein-3: a malaria protein inducing antibodies that promote Plasmodium falciparum killing by cooperation with blood monocytes. Blood 84, 1594-1602.

Osier, F.H., Fegan, G., Polley, S.D., Murungi, L., Verra, F., Tetteh, K. K., Lowe, B., Mwangi, T., Bull, P.C., Thomas, A. W., Cavanagh, D. R., Mcbride, J.S., Lanar, D. E., Mackinnon, M. J., Conway, D. J. and Marsh, K. (2008). Breadth and magnitude of antibody responses to multiple Plasmodium falciparum merozoite antigens are associated with protection from clinical malaria. Infection and Immunity 76, 2240-2248

Pearce, E. J. and Macdonald, A.S. (2002). The immunobiology of schistosomiasis. Nature Reviews Immunology 2, 499-511.

Polley, S. D., Conway, D. J., Cavanagh, D. R., Mcbride, J.S., Lowe, B. S., Williams, T. N., Mwangi, T. W. and Marsh, K. (2006). High levels of serum antibodies to merozoite surface protein 2 of Plasmodium falciparum are associated with reduced risk of clinical malaria in coastal Kenya. Vaccine 24, 4233-4246.

Polley, S. D., Tetteh, K. K., Cavanagh, D. R., Pearce, R. J., Lloyd, J. M., Bojang, K. A., Okenu, D. M., Greenwood, B. M., Mcbride, J. S. and Conway, D. J. (2003). Repeat sequences in block 2 of Plasmodium falciparum merozoite surface protein 1 are targets of antibodies associated with protection from malaria. Infection and Immunity 71, 1833-1842.

Reilly, L. J., Magkrioti, C., Cavanagh, D. R., Mduluza, T. and Mutapi, F. (2008). Effect of treating Schistosoma haematobium infection on Plasmodium falciparum-specific antibody responses. BMC Infectious Diseases 8, 158 .

Remoue, F., Diallo, T. O., Angeli, V., Herve, M., De Clercq, D., Schacht, A. M., Charrier, N., Capron, M., Vercruysse, J., Ly, A., Capron, A. and Riveau, G. (2003). Malaria co-infection in children influences antibody response to schistosome antigens and inflammatory markers associated with morbidity. Transactions of the Royal Society of Tropical Medicine and Hygiene 97, 361-364.

Silveira, A. M., Bethony, J., Gazzinelli, A., Kloos, H., Fraga, L. A., Alvares, M. C., Prata, A., Guerra, H. L., Loverde, P. T., CorreaOliveira, R. and Gazzinelli, G. (2002). High levels of IgG4 to Schistosoma mansoni egg antigens in individuals with periportal fibrosis. American fournal of Tropical Medicine and Hygiene 66, 542-549.
Sokal, R. R. and Rohlf, J. (1995). Biometry: The Principles and Practice of Statistics in Biological Research, Freeman and Company, New York.

Sousa-Figueiredo, J. C., Basanez, M. G., Mgeni, A. F., Khamis, I. S., Rollinson, D. and Stothard, J. R. (2008). A parasitological survey, in rural Zanzibar, of pre-school children and their mothers for urinary schistosomiasis, soil-transmitted helminthiases and malaria, with observations on the prevalence of anaemia. Annals of Tropical Medicine and Parasitology 102, 679-692.

Stothard, J. R. and Gabrielli, A. F. (2007). Schistosomiasis in African infants and preschool children: to treat or not to treat? Trends in Parasitology 23, 83-86.

Stothard, J.R., Sousa-Figuereido, J.C., Betson, M., Adriko, M., Arinaitwe, M., Rowell, C., Besiyge, F. and Kabatereine, N. B. (2011). Schistosoma mansoni infections in young children: when are schistosome antigens in urine, eggs in stool and antibodies to eggs first detectable? PLoS Neglected Tropical Diseases 5, e938.

Taylor, P. and Mutambu, S. L. (1986). A review of the malaria situation in Zimbabwe with special reference to the period 1972-1981. Transactions of the Royal Society of Tropical Medicine and Hygiene 80, 12-19.

Taylor, R. R., Allen, S. J., Greenwood, B. M. and Riley, E. M. (1998). IgG3 antibodies to Plasmodium falciparum merozoite surface protein 2 (MSP2): increasing prevalence with age and association with clinical malaria. American Fournal of Tropical Medicine and Hygiene 58, 406-413.

Theisen, M., Soe, S., Oeuvray, C., Thomas, A. W., Vuust, J. Danielsen, S., Jepsen, S. and Druilhe, P. (1998). The glutamate-rich protein (GLURP) of Plasmodium falciparum is a target for antibodydependent monocyte-mediated inhibition of parasite growth in vitro. Infection and Immunity 66, 11-17.

Uneke, J. C. and Egede, M. U. (2009). Impact of urinary schistosomiasis on nutritional status of school children in south-eastern Nigeria. Internet $\mathcal{F}$ Health 9: Available: http://www.ispup.com/journal/the_internet_journal_of_ health/volume_9_number_1_12/article/impact-of-urinary-schistosomiasis-onnutritional-status-of-school-children-in-south-eastern-nigeria.html. Accessed 07 July 2011.

Van Den Biggelaar, A. H. and Holt, P. G. (2010). 99th Dahlem conference on infection, inflammation and chronic inflammatory disorders: neonatal immune function and vaccine responses in children born in lowincome versus high-income countries. Clinical and Experimental Immunology 160, 42-47.

Van Den Biggelaar, A. H., Van Ree, R., Rodrigues, L. C., Lell, B., Deelder, A. M., Kremsner, P. G. and Yazdanbakhsh, M. (2000). Decreased atopy in children infected with Schistosoma haematobium: a role for parasite-induced interleukin-10. Lancet 356, 1723-1727.

Wilson, S., Jones, F. M., Mwatha, J. K., Kimani, G., Booth, M., Kariuki, H. C., Vennervald, B.J., Ouma, J.H., Muchiri, E. and Dunne, D.W. (2008). Hepatosplenomegaly is associated with low regulatory and Th2 responses to schistosome antigens in childhood schistosomiasis and malaria coinfection. Infection and Immunity 76, 2212-2218.

Woolhouse, M. E., Mutapi, F., Ndhlovu, P. D., Chandiwana, S. K. and Hagan, P. (2000). Exposure, infection and immune responses to Schistosoma haematobium in young children. Parasitology 120, 37-44.

Woolhouse, M. E. J., Taylor, P., Matanhire, D. and Chandiwana, S. K. (1991). Acquired immunity and epidemiology of Schistosoma haematobium. Nature 351, 757-759.

World Health Organisation (2002). Prevention and control of schistosomiasis and soil-transmisted helminthiasis. In WHO technical Report Series World Health Organisation, Geneva.

Zhang, Z., Wu, H., Chen, S., Hu, L., Xie, Z., Qiu, Y., Su, C., Cao, J. P., Wu, Y., Zhang, S. and Wu, G. (1997). Association between IgE antibody against soluble egg antigen and resistance to reinfection with Schistosome japonicum. Transactions of the Royal Society of Tropical Medicine and Hygiene 91, 606-608. 